\title{
DELTA-K CORRELATION OF FATIGUE CRACK GROWTH RATES UNDER GENERAL MONOTONIC YIELDING
}

\section{S.A. Seetharam and P.K.Dash}

Structural Sciences Division, NationalAeronautical Laboratory

Bangalore, 560 017, India

tel: $(91)-(0812)-(562179)$

Linear Elastic Fracture Mechanics, LEFM, principles are successfully used to characterize the behavior of flawed structures and components under monotonic loading. Crack length increment, da, correlates with maximum stress intensity factor, $\mathrm{K}_{\max }$, when the monotonic plastic zone size is small. Cracks can grow under cyclic loading even at stress levels lower than that required for crack extension under static loading. Paris et al. [1,2] established the correlation between crack growth rate, da/dN, and stress intensity factor range, delta-K, of the load cycle. Aplication of LEFM principles to crack extension under monotonic cyclic loading can be seen as:

\begin{tabular}{llll} 
loading & $\begin{array}{l}\text { response } \\
\text { parameter }\end{array}$ & $\begin{array}{l}\text { correlating } \\
\text { parameter }\end{array}$ & restriction \\
\hline $\begin{array}{l}\text { Monotonic } \\
\text { da }\end{array}$ & Kmax & $\begin{array}{l}\text { Monotonic plastic } \\
\text { zone size small }\end{array}$ \\
Cyclic & $\mathrm{da} / \mathrm{dN}$ & delta-K & $?$
\end{tabular}

A small monotonic plastic zone implies a still smaller cyclic plastic zone. Therefore Small Scale Monotonic Yielding (SSMY) becomes a 'sufficient' condition for a valid application of LEFM parameters to fatigue crack growth. However, fatigue crack growth is essentially a cyclic process in the low and intermediate growth rate regimes and hence depends on the cyclic variation of strain rather than on maximum strain ahead of the crack tip. Rice [3] demonstrated, for perfectly plastic as well as for strain hardening material with stable hysteresis loop, that the strain range ahead of the crack tip depends on the applied stress range and is relatively insensitive to the maximum applied stress. It is, therefore, reasonable to expect that applied delta-K can represent fatigue crack growth rate in the low and intermediate growth rate regimes even though $\mathrm{K}_{\max }$ is not defined due to large scale tensile yielding. There is, therefore, a need to reassess the 'necessary' Small Scale Yielding (SSY) condition since the small monotonic plastic zone requirement is too restrictive. Rice [3] and Johnson and Paris [4] pointed out that under net section yielding the unloading deformation at the crack tip can be elastic provided the amplitude of loading is small. Hence 
delta-K can still represent fatigue crack growth rates. Frost, Pook and Denton [5] found that delta- $K$ described growth rate even under net section yielding in some materials in high stress ratio tests.

Most literature reviews like Suresh and Ritchie's [6] and Brown's [7], still maintain that monotonic plastic zone be small for obtaining da/dN -delta-K correlation under fatigue loading. Brown et al. [8], in their critical comparison of parameters for high strain fatigue crack growth maintain that LEFM is applicable only for stress range less than one third the flow stress value. For stress values beyond this limit they have evaluated delta-J, delta-CTOD, Crack Tip Opening Displacement, and cyclic plastic zone size as possible crack growth rate correlating parameters. However, their crack growth rate data under uni-axial, equi-biaxial and torsional loading at $\mathrm{R}=-1.0$ do not rule out effective stress intensity factor range as an appropriate correlating parameter. Raju [9] discussed the effect of non-LEFM conditions on fatigue crack growth as follows: large scale monotonic plasticity makes the growth rate asymptotically approach infinity at a reduced fracture toughness value. Large cyclic plasticity makes this approach more rapid. Kendal et al. [10] obtained, in low carbon steel specimens under general tensile yielding, short crack growth rates identical to those of a long crack in the range of applied delta-K where crack closure was absent. They rightly pointed out the relatively insignificant role played by monotonic large scale yielding and the major role of crack closure in the anomalous short fatigue crack growth at lower delta-K ranges.

It is suggested in this report that cyclic plastic zone and not the monotonic plastic zone size be small compared to crack length for application of LEFM to fatigue crack growth in the technologically significant regimes I and II of the $\mathrm{da} / \mathrm{dN}$ vs. delta-K plot. Small cyclic plastic zone and absence of crack closure make high stress ratio fatigue crack growth experiments ideal for understanding the limitation of LEFM principles to fatigue crack growth. Such an experimental program is discussed below.

The material used in this investigation was the BSS L-72, $2 \mathrm{~mm}$ thick sheet. Constant amplitude loading tests were performed at a stress ratio of 0.7 in a 10 ton Instron servo hydraulic testing machine. Single edge notched tension (SENT) specimens were used in the experiment with a $6 \mathrm{~mm}$ starter notch. Test frequency was of the order of $15 \mathrm{~Hz}$. For tests at higher stress levels, specimens were prepared by fatigue precracking at $R=-1$ at low stress levels. The specimen was then machined by spark erosion to leave a 50 to 100 micron fatigue crack. Test frequency was kept around $0.1 \mathrm{~Hz}$. Further, the specimens were cycled at intermediate load levels for a few cycles and gradually the load level was taken to the required value. This was necessary as some specimens failed before reaching the required load level in the very first cycle in spite of the low frequency. Crack extension was monitored by a travelling microscope with a $100 \mathrm{X}$ magnification. Maximum stress values ranging from 80 to $370 \mathrm{MPa}$ (static yield stress $=$ $330 \mathrm{MPa}$ ) were used to obtain growth rates both under small scale as well as general tensile yielding conditions. 
Crack growth rate versus stress intensity factor range data correlations are shown in Fig. 1. It is seen that even at $S_{\max }=370 \mathrm{MPa}$ good da/dN delta-K correlation exists at lower growth rate range. At higher growth rates it tends to asymptotically approach infinity at a lower critical stress intensity factor range. This is due to the stress level dependence of fracture toughness and the presence of static modes of failure during fatigue cycling which is a $\mathrm{K}_{\max }$ controlled process [9]. In the lower growth rate regime, crack growth, being essentially a cyclic process, is dependent on the cyclic variation of crack tip strain and is independent of the maximum strain. The stress intensity factor range adequately represents the strain range (due to a small cyclic plastic zone and more importantly absence of crack closure) even though $\mathrm{K}_{\max }$ is not defined due to general tensile plasticity.

The family of growth rate curves at. one stress ratio (Fig. 1) can be represented by a Forman type equation,

$$
d a / d N=C \frac{\left(\Delta K-\Delta K_{t h}\right)^{*}(\Delta K)^{m}}{\left(K_{c r}\left(S_{\max }\right)-K_{\max }\right)}
$$

where the fracture toughness of the material is considered to be a function of the maximum applied stress. An approximate estimate of the stress dependent fracture toughness $\mathrm{K}_{a \mathrm{c}}$, is obtained as follows: Based on fracture toughness and critical crack opening displacement criteria for fracture, the functional relationships between the applied stress and critical crack length are shown in Fig. 2 for a central crack. From the pairs of stress versus critical crack length data points (based on COD condition) a stress dependent fracture toughness curve is derived and is shown in Fig. 3. The stress dependent $\mathrm{K}_{\mathrm{cr}}$ values are used in the denominator of (1). The values of $\mathrm{C}$ and $\mathrm{m}$, in (1), are determined by a regression analysis on the da/dN - delta-K data at $S_{\max }=80 \mathrm{MPa}$ shown in Fig. 1. The computed crack growth rate curves, from (1), are shown in Fig. 4 along with the experimental data. It is observed that the stress dependent (large scale monotonic yielding) growth rate behavior (in regime-III) is adequately represented by (1).

The results, presented here, suggest that the 'necessary' SSY condition for $\mathrm{da} / \mathrm{dN}$ - delta-K correlation (in regimes-I and II) is that the cyclic plastic zone be small compared to the relevant geometric dimension of the crack.

At lower stress ratios, crack closure drastically reduces further development of the cyclic plastic zone and it is quite likely that the small scale cyclic yielding condition is, almost always, satisfied except in tests under gross cyclic plastic loading. Breakdown of da/dN - applied delta-K correlation is, more likely, due to the effect of crack closure in altering the effective stress intensity factor range rather than due to any violation of the SSY condition.

Acknowledgement: Discussion with Dr. K.N. Raju and Dr. R.M.S. Gowda is gratefully acknowledged. This investigation was carried out with the financial support from AR\&DB, Ministry of Defence, Government of India. 


\section{REFERENCES}

[1] P.C, Paris, M.P. Gomez and W.E. Anderson, in "The Trends in Engineering", University of Washington, Seattle 13 (1969) 9-14.

[2] P.C. Paris and F. Erdogan, Journal of Basic Engineering 85 (1965) 528-534.

[3] J.R. Rice, in Fatigue Crack Propagation, STP 415, ASTM, Philadelphia (1967) 247-311.

[4] H.H. Johnson and P.C. Paris, Engineering Fracture Mehanics 1 (1968) 3-45.

[5] N.E. Frost, IP. Pook and K. Denton, Engineering Fracture Mechanics 3 (1971) 109-126.

[6] S. Suresh and R.O. Ritchie, International Metals Reviews 29 (1984) 445-475.

[7] M.W,.Brown, Proceedings of the Institute of Mechanical Engineers (London) 202 (1988) 19-29.

[8] M.W. Brown, E.R. de los Rios and K.J. Miller, in Basic Questions in Fatigue, STP 924, ASTM, Philadelphia (1988) 233-259.

[9] K.N. Raju, in "Workshop Notes on Fracture, Fatigue and Failure Analysis, Part III", National Aeronautical Laboratory, Bangalore (1979).

[10] J.M. Kendal, M.N. James and J.F. Knott, in Proceedings ofthe First International Conference on Short Fatigue Cracks (1986) 241-258.

14August 1991

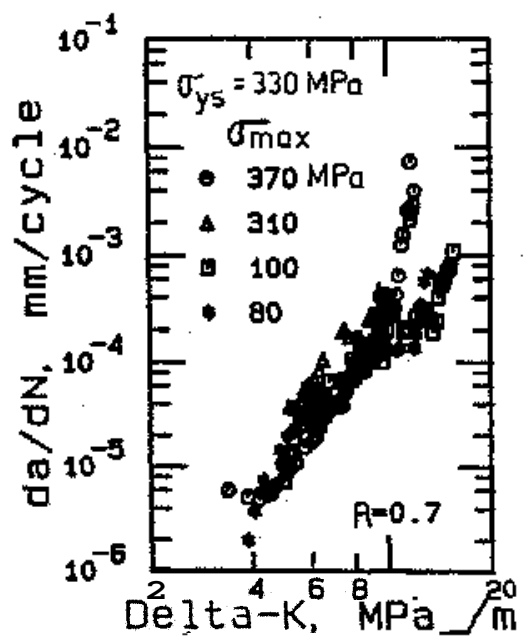

Figure 1. da/dN - $\Delta \mathrm{K}$ correlation under large and small scale monotoni yielding. 


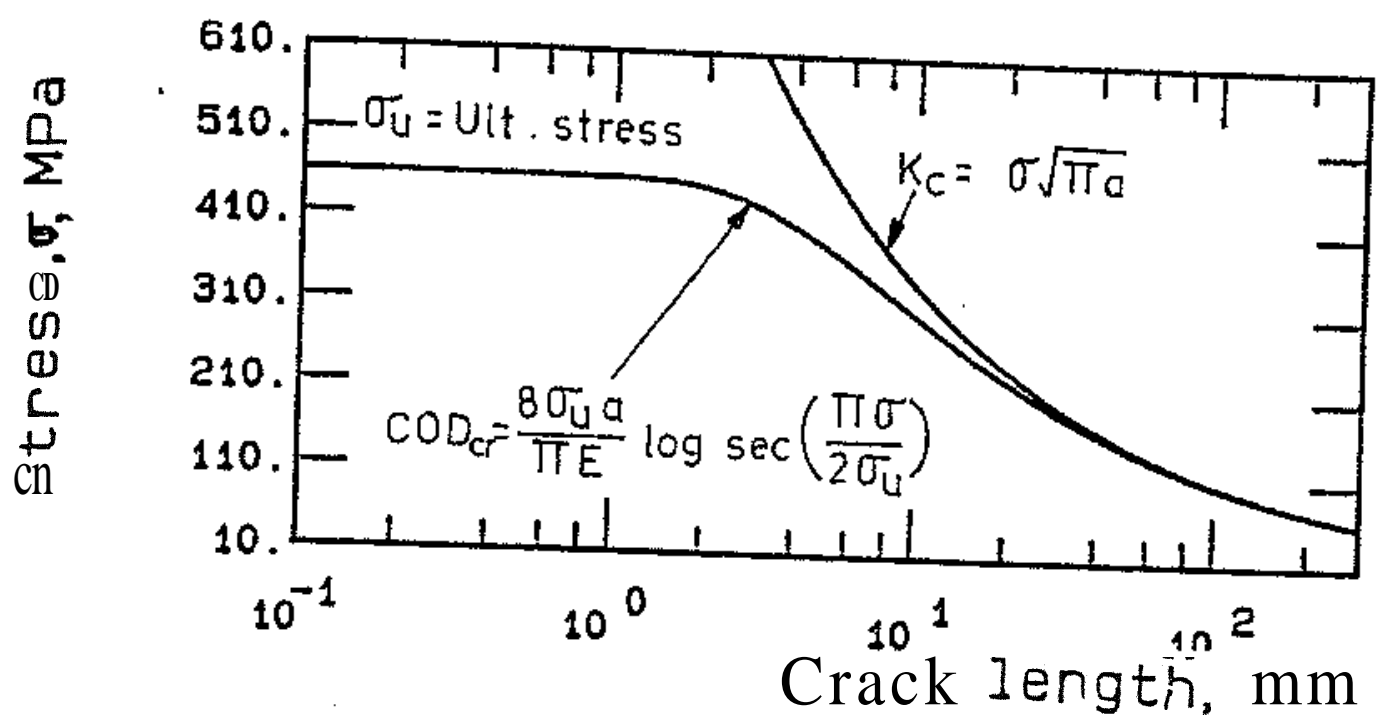

Figure 2, Stress vs. critical crack length relations from $\mathrm{K}$ and COD
criteria; centre crack geometry.

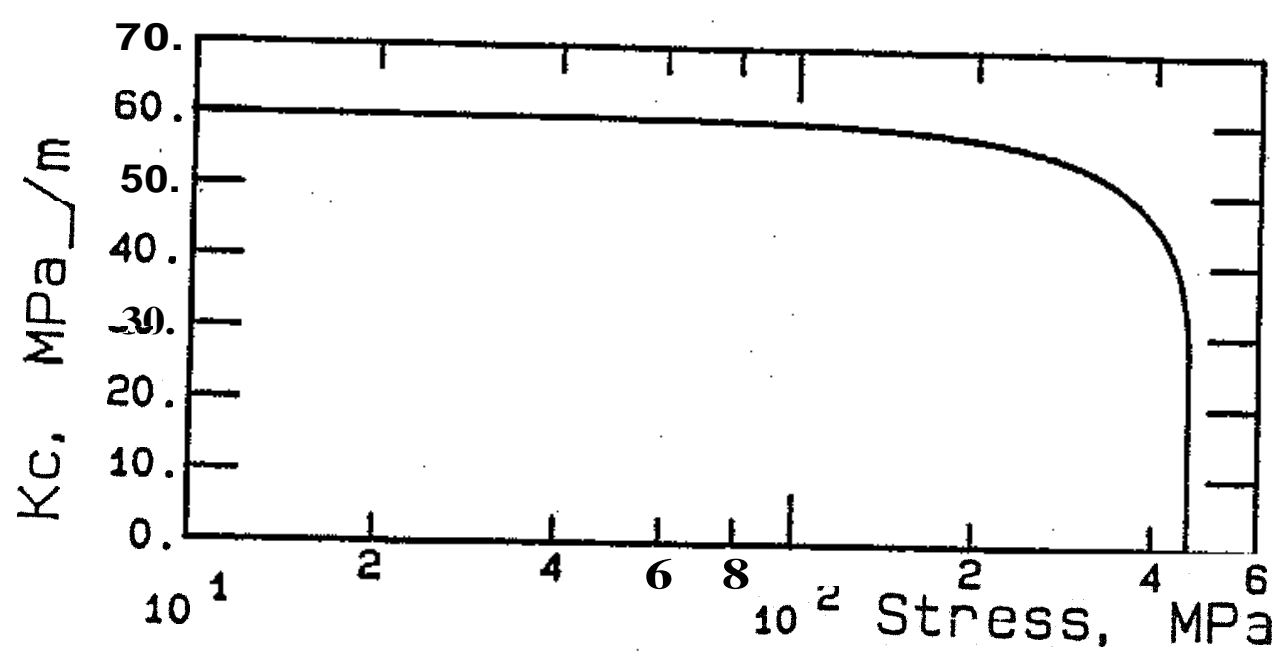

Figure 3. Stress dependent $K_{c}$ values from COD criterion in Fig. 2. 


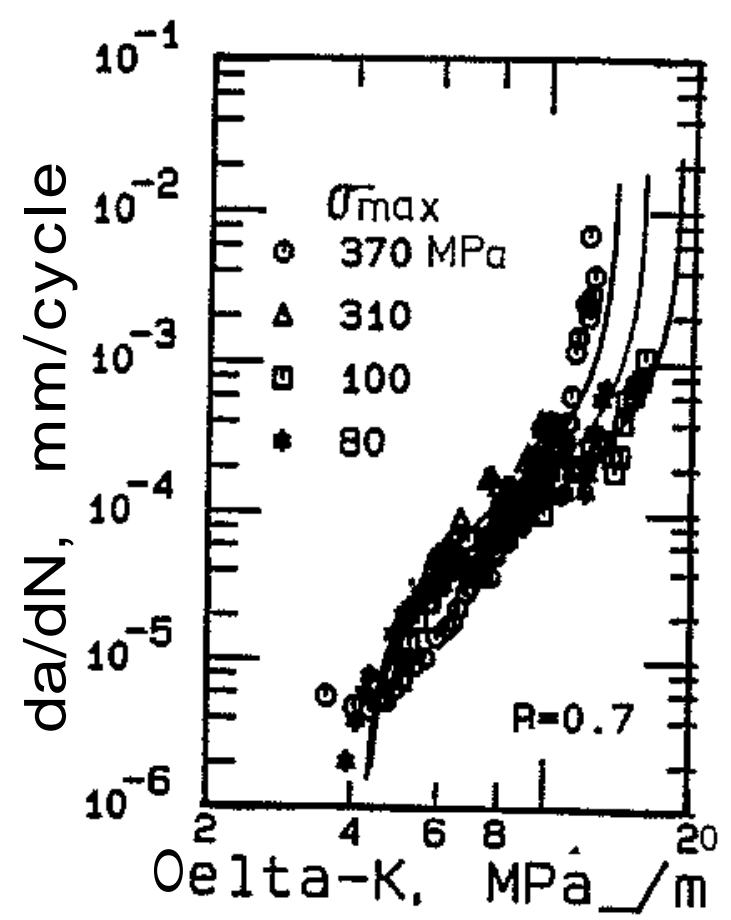

Figure 4. Forman type equetion fit to the data in Fig. 1. 